Bangladesh J. Plant Taxon. 28(1): 155-169, 2021 (June)

(C) 2021 Bangladesh Association of Plant Taxonomists

https://doi.org/10.3329/bjpt.v28i1.54215

\title{
GENETIC DIVERSITY, HERITABILITY AND GENETIC ADVANCE OF SOLANUM MELONGENA L. FROM THREE SECONDARY CENTERS OF DIVERSITY
}

\author{
Debi Rani Datta ${ }^{1,3}$, M.Y. RafiI ${ }^{1,2}$, Azizah Misran $^{2}$, Mashitah Jusoh $^{2}$, \\ Oladosu Yusuff ${ }^{1}$, Nadzirah M. Sulaiman ${ }^{1}$ and Jalloh Momodu ${ }^{2,4}$ \\ Institute of Tropical Agriculture and Food Security, Universiti Putra Malaysia, \\ 43400 Serdang, Selangor, Malaysia
}

Keywords: Genetic diversity; Heritability and Genetic advance; PCV and GCV.

\begin{abstract}
Indo-Birmanian is considered as the domesticated region and primary center of eggplant diversity from where it spread to other secondary centers of diversity. In this study, the genetic diversity among 56 eggplant genotypes from three secondary centers of diversity (Bangladesh, Malaysia and Thailand) was assessed using 11 morphological traits. The experiment was laid in a complete randomized block design with three replications. A wide significant variation was observed for all the morphological traits, and highly significant differences among the three centers of diversity. High heritability and genetic advance was found for different traits i.e. fruit length, fruit diameter, fruit girth, fruit length to width ratio, average fruit weight, number of fruits per plant, fruit yield per plant, plant height and number of primary branches per plant. The selected best traits i.e. number of fruits per plant, average fruit weight and fruit yield per plant showed high heritability along with high genetic advance and less environmental influence but the high value of PCV and GCV. So these traits could be useful for selection criteria in the future breeding program. These results are relevant for evolutionary studies, breeding programs, and management of eggplant genetic resources.
\end{abstract}

\section{Introduction}

Eggplant (Solanum melongena L.) is an important vegetable crop belonging to the Solanaceae family. It is also known as brinjal, aubergine or guinea squash that are widely cultivated in the tropics, subtropics and temperate regions. The eggplant name is obtained from egg-shaped fruit of some cultivars (Akhter et al., 2012). It is a perennial crop but commercially cultivated as an annual vegetable crop for its immature, unripe fruits which are used in making various types of cooked curries. It has high nutritive value, high market demand and the most cost-effective and profitable among other vegetables. It is also known as the "king of vegetables" for its versatility use in Indian food (Dhaka et al., 2017). Some ayurvedic properties also appear in eggplant and it is helpful for diabetic patients (Fraikue, 2018). It acts as an excellent medicine for those who suffer from liver trouble (Akhter et al., 2012). In spite of the nutritional and economic importance of eggplant, there are limited studies on eggplant breeding program (Daunay, 2008). For addressing breeding challenges and improvement of eggplant, the use of wide and exotic germplasm has been extensively adopted (Muñoz-Falcon et al., 2009) and a significant reduction

${ }^{1}$ Laboratory of Climate-Smart Food Crop Production, Institute of Tropical Agriculture and Food Security, Universiti Putra Malaysia, 43400 Serdang, Selangor, Malaysia.

${ }^{2}$ Dept. of Crop Science, Faculty of Agriculture, Universiti Putra Malaysia, 43400 Serdang, Selangor, Malaysia.

${ }^{3}$ Bangladesh Agricultural Research Institute, Gazipur, Dhaka, Bangladesh.

${ }^{4}$ Sierra Leone Agricultural Research Institute, P.MB.1313, Tower Hill, Freetown, Sierra Leone.

*Corresponding author. E-mail: mrafii@upm.edu.my 
in genetic diversity of modern black eggplants cultivars was reported. However, this reduction can be overcome by incorporating black fruit traits from genetically distant materials into the genetic background of elite cultivars thereby increasing the genetic base of this cultivar (RodriguezBurruezo et al., 2008). Assessment of relationship and diversity of the cultivated genotype helps in the understanding crop evolution, establishment of conservation strategies and utilization of genetic resources. The evolution and domestication of eggplant has been studied using molecular, morphological and historical analyses.

Eggplant was generally believed to be domesticated in Southeast Asia from Solanum incanum L. the wild relative of commercial cultivar. This hypothesis was supported by molecular, morphological and fertility of $\mathrm{F}_{1}$ hybrids crossed with Solanum melongena (Muñoz-Falcòn et al., 2009). Although it is unknown how S. incanum reached in the Indo-Birmanian center of diversity which is naturally distributed in the Middle East and Africa. It has been speculated that the dispersal can be intentionally or unintentionally through oceanic current from Africa to India (Lester and Hasan, 1991). As in the case of tomato, domestication outside the area where is the wild ancestor are naturally distributed resulted in an important genetic constriction (Daunay, 2008). Dispersal of the eggplant from Indo-Birmanian region which is considered as the primary center of diversity to other regions resulted in the crop diversification due to micro-evolutionary forces such as artificial and natural selection, gene flow, recombination, and mutation has led to the accumulations of genetic variability in numerous secondary centers of diversity (Hurtado et al., 2012). Therefore, assessment of genetic diversity of distant geographically centers of diversity will assist in understanding the structure of eggplant genetic variability, crop improvement and conservation of genetic resources. Similar studies have been performed on several crops such as sorghum (Strelchenko et al., 2010), oil palm (Myint et al., 2019) and rice (Sarif et al., 2020).

Morphological characterization has proven useful in studying the relationship and diversity of different varieties of eggplant. Characterization using agronomic traits is essential in crop improvement breeding programs. The morphological characterization for eggplant has been define by the European Eggplant Genetic Resources Network (EGGNET) (Vander Weerden and Barendse, 2006) which have been validated and used in characterization of eggplant breeding materials in numerous studies (Muñoz-Falcòn et al., 2009; Rodriguez-Burruezo et al., 2008; Sulaiman et al., 2020). Morphological diversity is the first issue of description and discrimination of genetic resources (Smith and Smith, 1989; Shrestha, 2013). Low genetic diversity was reported, among the dark purple to black color eggplant fruits (Muñoz-Falcòn et al., 2009; Boyaci et al., 2015). Hence, creation of variation through mutation, hybridization and approaches of biotechnology is a high-priced and time dependent method (Boyaci et al., 2015). So, it is necessary to characterize collected germplasm (populations) to identify lines suited for new variety development (Boyaci et al., 2015). Genetic diversity studies based on quantitative traits are of interest to plant breeders as such traits can be rapidly and easily scored using low cost methods (Myint et al., 2019). For this method, no sophisticated equipment is required and the data can be easily recorded without specific biochemical or molecular techniques.

Heritability is defined as the proportion of the total variation in a given phenotypes within a population that is attributable to genetic variance. The genetic makeup of a plant and the surrounding environment regulate the phenotypic expression of the plant trait (Pujer et al., 2017). Consequently, the magnitude of variability available in some main profitable characters and their heritability together with genetic advances will be fruitful to the breeders for selecting effectively and constructing sound breeding programs. Knowledge regarding heritability assists plant breeders to forecast the nature of the progeny, to create a proper selection and to evaluate the expansion of genetic advancement through selection (Khatun et al., 2010). Development of superior yielding genotypes not only depends on yield trait but also influenced by many other characters because 
yield is a complex character. The interrelation between yield and yield attributing traits can be determined by correlation coefficient which provides information on nature, extent and selection direction. Knowledge on genetic parameters is also important for improvement in crops. The objective of this research was to identify and classify variations among eggplant accessions from three different centres of diversity. These results will be relevant for evolutionary studies, breeding programs, management and conservation of eggplant genetic resources.

\section{Materials and Methods}

Experiment location, design and plant materials

'This experiment was done from mid-July to mid-December, 2018 at Ladang 15, Faculty of Pertanian in Universiti Putra Malaysia. This place located geographically between $2^{\circ} 59^{\circ}$ north latitude to $101^{\circ} 43^{`}$ east latitude, with $55 \mathrm{~m}$ altitude. The randomized complete block design (RCBD) along with three replications was followed. Fifty-six eggplant genotypes seed (Table 1) collected from Bangladesh, Malaysia and Thailand were used in this study.

\section{Eggplant genotypes, seedlings, transplantation and their management}

Seeds were placed on a tray for germination which filled with peat moss soil. Each tray containing 104 holes and 1-2 seeds were sown per hole. Twenty one days old seedlings were transferred from tray to polybag and kept in net house until transplanting in the field. The polybags were filled with soil and peat moss at 2:1 ratio. Forty-five days old seedlings were transplanted in the field. Just one seedling was transplanted in each hole. Seedlings were transplanted at a distance of $60 \mathrm{~cm}$ from plant to plant and $80 \mathrm{~cm}$ from row to row. Ten seedlings were transplanted per accession per replication. All recommended cultural practices were followed as per package of practices to raise a healthy crop.

\section{Data collection}

Data were collected from randomly selected three plants of each genotype in every replication for plant height, primary branches per plant, fruit length, fruit diameter, fruit girth, fruit length to width ratio, days to first flowering, days to 50 percent flowering, individual fruit weight, number of fruits per plant and average yield per plant. All of these traits were measured from all accessions at each of replications, as shown in Table 2. Fruits were harvested at proper maturity stage. Maturity stage was determined by firmness and external glossiness of fruits. All data were taken according to eggplant descriptor of International Board for Plant Genetic Resources (IBPGR, Italy).

\section{Data analyses}

All the morphological traits were subjected to analysis of variance (ANOVA) using SAS 9.4 software. Least significant difference (LSD) was used for mean comparison at 5\% level of significance. REML (Restricted Maximum Likelihood) of proc varcomp in SAS 9.4 was used to estimate variance components. Proc corr of SAS command was used to determine simple phenotypic correlation analysis. NTSYS-PC software (version 2.1) was used for clustering (UPGMA) and principal component analysis (PCA) to analyze diversity.

The different genetic parameters such as phenotypic coefficient of variation, genotypic coefficient of variation, broad-sense heritability and genetic advance as a percentage of the mean (GAM), were estimated using the formula given by Myint et al. (2019) and Pujer et al. (2017). 
Table 1. List of selected eggplant genotypes.

\begin{tabular}{|c|c|c|c|}
\hline Sl.No. & Accession code & Source code & Collection country \\
\hline 1 & BB1 & China 3 & Bangladesh \\
\hline 2 & BB3 & MuktaJhuri & Bangladesh \\
\hline 3 & BB4 & MuktaKeshi & Bangladesh \\
\hline 4 & BB5 & Chinese Macra & Bangladesh \\
\hline 5 & BB6 & BARI Eggplant 2 & Bangladesh \\
\hline 6 & BB7 & Tal Begun & Bangladesh \\
\hline 7 & BB8 & Pahuja seed co. & Bangladesh \\
\hline 8 & BB9 & Pahuja seed co. & Bangladesh \\
\hline 9 & BB10 & Laskar seed & Bangladesh \\
\hline 10 & BB11 & Singhnath & Bangladesh \\
\hline 11 & BB12 & BARI Eggplant1 & Bangladesh \\
\hline 12 & BB13 & BARI Eggplant4 & Bangladesh \\
\hline 13 & BB14 & BARI Eggplant5 & Bangladesh \\
\hline 14 & BB15 & BARI Eggplant6 & Bangladesh \\
\hline 15 & BB16 & BARI Eggplant7 & Bangladesh \\
\hline 16 & BB17 & BARI Eggplant8 & Bangladesh \\
\hline 17 & BB18 & BARI Eggplant9 & Bangladesh \\
\hline 18 & BB19 & BARI Eggplant 10 & Bangladesh \\
\hline 19 & BB20 & 220 & Bangladesh \\
\hline 20 & BB21 & 217 & Bangladesh \\
\hline 21 & BB22 & 253 & Bangladesh \\
\hline 22 & BB23 & 222 & Bangladesh \\
\hline 23 & BB24 & 275 & Bangladesh \\
\hline 24 & BB26 & 288 & Bangladesh \\
\hline 25 & BB27 & 291 & Bangladesh \\
\hline 26 & BB28 & 311 & Bangladesh \\
\hline 27 & BB30 & 330 & Bangladesh \\
\hline 28 & BB31 & 338 & Bangladesh \\
\hline 29 & BB32 & 317 & Bangladesh \\
\hline 30 & BB33 & 346 & Bangladesh \\
\hline 31 & BB34 & 350 & Bangladesh \\
\hline 32 & BB35 & 262 & Bangladesh \\
\hline 33 & BB36 & 357 & Bangladesh \\
\hline 34 & BM3 & 214, Mini eggplant & Malaysia \\
\hline 35 & BM4 & 311, Round purple & Malaysia \\
\hline 36 & BM5 & 330,White eggplant & Malaysia \\
\hline 37 & BM6 & 418, Purple king & Malaysia \\
\hline 38 & BM7 & 428, Nyonya eggplant & Malaysia \\
\hline 39 & BM8 & 313, Little Nyonya & Malaysia \\
\hline 40 & BM9 & 312, Super Naga & Malaysia \\
\hline 41 & BM10 & MTe2 & Malaysia \\
\hline 42 & BT1 & $636 / 2559$ & Thailand \\
\hline 43 & BT2 & $01387 / 2552$ & Thailand \\
\hline 44 & BT3 & $1845 / 2338$ & Thailand \\
\hline 45 & BT4 & $00558 / 2551$ & Thailand \\
\hline 46 & BT5 & Parquy & Thailand \\
\hline 47 & BT6 & $969 / 2560$ & Thailand \\
\hline 48 & BT7 & $01451 / 2551$ & Thailand \\
\hline 49 & BT8 & $914 / 2558$ & Thailand \\
\hline 50 & BT9 & $01450 / 2551$ & Thailand \\
\hline 51 & BT10 & $01166 / 2551$ & Thailand \\
\hline 52 & BT11 & $762 / 2556$ & Thailand \\
\hline 53 & BT13 & $1745 / 2560$ & Thailand \\
\hline 54 & BT15 & $548 / 2558$ & Thailand \\
\hline 55 & BT16 & $01200 / 2553$ & Thailand \\
\hline 56 & BT17 & $548 / 2556$ & Thailand \\
\hline
\end{tabular}

Note: BB: Brinjal Bangladesh, BM: Brinjal Malaysia, BT: Brinjal Thailand. 
Table 2. List of eleven quantitative characters of eggplants.

\begin{tabular}{|c|c|}
\hline Traits & Method of evaluation \\
\hline Fruit Length (FL, cm) & $\begin{array}{l}\text { The average length of } 10 \text { marketable fruits per Plant from top to } \\
\text { bottom was taken }\end{array}$ \\
\hline Fruit Diameter $(\mathrm{FD}, \mathrm{cm})$ & $\begin{array}{l}\text { Measured along the middle part of } 10 \text { harvestable fruit per plant by } \\
\text { Caliper and finally, the average value was converted into } \mathrm{cm}\end{array}$ \\
\hline $\begin{array}{l}\text { Fruit Length to Width Ratio (FLWR, } \\
\text { ratio) }\end{array}$ & $\begin{array}{l}\text { The value of fruit diameter was divided by the value of fruit length of } \\
\text { individual }\end{array}$ \\
\hline Fruit Length to Width Ratio (FLWR) & $\begin{array}{l}\text { The value of fruit diameter was divided by the value of fruit length of } \\
\text { individual plant }\end{array}$ \\
\hline Fruit Girth (FG, cm) & $\begin{array}{l}\text { Measured along the middle part of } 10 \text { harvestable fruit per plant by } \\
\text { measuring tape and finally, the average value was taken }\end{array}$ \\
\hline $\begin{array}{l}\text { Fruit Length to Width Ratio (FLWR, } \\
\text { ratio) }\end{array}$ & $\begin{array}{l}\text { The value of fruit diameter was divided by the value of fruit length of } \\
\text { individual }\end{array}$ \\
\hline Average Fruit Weight ( FW, g) & The average weight of 10 harvestable fruit per plant was taken \\
\hline Number of Fruits per plant (NF, no) & Total number of fruits harvested from individual plant \\
\hline Average Yield per plant (YPP, g) & $\begin{array}{l}\text { Total fruits harvested from each selected plant in each replication \& } \\
\text { each harvest was weighted and summed up }\end{array}$ \\
\hline Days to first flowering (DF, days) & $\begin{array}{l}\text { Days from transplanting to the first flowering of every plant of each } \\
\text { accession was recorded }\end{array}$ \\
\hline $\begin{array}{l}\text { Days to fifty percent flowering (DFF, } \\
\text { days) }\end{array}$ & $\begin{array}{l}\text { Days from transplanting to the first flowering of fifty percent plant of } \\
\text { every genotype were recorded }\end{array}$ \\
\hline Plant Height (PH, cm) & $\begin{array}{l}\text { Length of the main stem from the ground to tip of the stem was } \\
\text { measured at } 90 \text { Days after Transplanting (DAS) }\end{array}$ \\
\hline Number of Primary Branches (PB, no) & $\begin{array}{l}\text { Number of primary branches of the selected plant was recorded at } 90 \\
\text { DAS }\end{array}$ \\
\hline
\end{tabular}

These traits include the following formulas:

a) Phenotypic Coefficient of Variation (PCV)

$$
\operatorname{PCV}(\%)=\frac{\sqrt{\sigma^{2} p}}{\bar{x}} \times 100
$$

Here, phenotypic variance i.e. $\sigma^{2} \mathrm{p}$ and $\mathrm{X}$ is the mean of a specific trait

b) Genotypic Coefficient of Variation (GCV),

$$
\operatorname{GCV}(\%)=\frac{\sqrt{\sigma^{2} g}}{\bar{X}} \times 100
$$

Here, $\sigma^{2} \mathrm{~g}$ is genotypic variance and $\mathrm{X}$ is expressed as a mean of a specific trait.

PCV and GCV were grouped into as low (0-10\%), medium (10-20\%) and high (> 20\%) by Sivasubramanian and Menon (1973).

c) Heritability in broad sense $\left(\mathrm{H}_{\mathrm{b}}{ }^{2}\right)$,

$$
\mathrm{H}_{\mathrm{b}}^{2}=\frac{\sigma^{2} g}{\sigma^{2} p} \times 100
$$

The heritability value was grouped into three categories i.e. low (0 to $30 \%)$, moderate heritability from (30 to 60\%) and high means ( $\geq 60 \%$ ) as given by Burton and De vane (1953). 
d) Genetic Advance of Mean (GAM),

$$
\operatorname{GAM}(\%)=\mathrm{H}_{\mathrm{b}}{ }^{2} \times \frac{\sqrt{\sigma^{2} p}}{\bar{X}} \times \mathrm{k}
$$

Where $\mathrm{k}$ is constant (2.06 at $5 \%$ selection intensity), $\mathrm{x}$ is the mean of a specific trait. It is divided into low (i.e. 0 to $10 \%$ ) moderate from (10 to 20\%) and high value ( $\geq 20 \%$ ) (Johnson et al., 1955).

\section{Results and Discussion \\ Morphological traits}

All quantitative characters of this research showed a highly significant difference $(\mathrm{P} \leq 0.01)$ among the accessions, countries, and accessions within countries (Table 3a-b) except days to first flowering. This result indicates that a significant amount of genetic variation present among accessions, countries, and accessions within countries. The trait days to first flowering showed no significant effect among countries. There was no significant difference in genetic variation among replication except the traits days to fifty percent flowering, number of primary branches per plant and plant height. The mean performance of 56 accessions for different quantitative traits is presented in (Table 5). The yield per plant ranged from 127.18 (BB9) to $1545.83 \mathrm{~g}$ (BB6). The number of fruits per plant ranged from 0.89 to 47 which were recorded by BB32 and BT15 accessions respectively (Table 5). The accession BT6 recorded the lowest fruit weight $(7.52 \mathrm{~g})$ while the accession BB15 gave the highest fruit weight $(261.20 \mathrm{~g})$. The average weight of fruit in this study was to be $108.29 \mathrm{~g}$.

Table 3a. Mean Squares of Analysis of Variance among 56 accessions of eggplant.

\begin{tabular}{llllllll}
\hline SOV & df & FL & FD & FG & FW & FLWR & YPP \\
\hline Replications (R) & 2 & $1 \mathrm{~ns}$ & $0.04 \mathrm{~ns}$ & $0.41 \mathrm{~ns}$ & $88.08 \mathrm{~ns}$ & $7.94 \mathrm{~ns}$ & $978.43 \mathrm{~ns}$ \\
Accessions (A) & 55 & $70.88^{* *}$ & $7.61^{* *}$ & $78.19^{* *}$ & $11768.5^{* *}$ & $139.08^{* *}$ & $414451^{* *}$ \\
Countries (C) & $(2)$ & $711.83^{* *}$ & $10.87^{* *}$ & $109.58^{* *}$ & $81393.40^{* *}$ & $84.64 * *$ & $767384.3^{* *}$ \\
$\quad[\mathrm{~A} / \mathrm{C}]$ & $(53)$ & $46.7^{* *}$ & $7.49^{* *}$ & $77^{* *}$ & $9141.13^{* *}$ & $141.13^{* *}$ & $401132^{* *}$ \\
Error & 110 & 0.92 & 0.1 & 1.13 & 79.22 & 5.85 & 2786.81 \\
$\sigma^{2} \mathrm{a}$ & & 23.32 & 2.5 & 25.69 & 3896.4 & 44.41 & 137232 \\
$\sigma^{2} \mathrm{e}$ & & 0.92 & 0.1 & 1.11 & 79.22 & 5.85 & 2754.5 \\
\hline
\end{tabular}

*Significant at $0.05, * *$ Highly significant at 0.01 and ns= non-significant, SOV: Sources of Variation, FL: Fruit Length, FD: Fruit Diameter, FG: Fruit Girth, FLWR: Fruit Length to Width Ratio, FW: Average Fruit Weight, YPP: Yield Per Plant, $d f=$ degrees of freedom, $\sigma 2 \mathrm{a}=$ accession variance, $\sigma 2 \mathrm{e}=$ error variance, $[\mathrm{A} / \mathrm{C}]=$ Accession within Countries,

\section{Estimation of genetic variations}

The phenotypic variances $\left(\sigma^{2} p\right)$ for all characters were greater than the genotypic variances $\left(\sigma^{2} \mathrm{~g}\right)$ (Table 4). Similarly, the PCV (Phenotypic Coefficient of Variation) was also higher than the GCV (Genotypic Coefficient of Variation). The phenotypic coefficient of variation (PCV) and genotypic coefficient of variation (GCV) estimation ranged from 8.55-113.98\% and 7.91-110.85 $\%$ respectively. The highest PCV was observedfor trait fruit length to width ratio (113.98\%) and followed by number of fruits per plant (111.43\%) and fruit yield per plant (68.19\%). Similarly, the maximum GCV was observed for traits number of fruits per plant (110.85\%) and followed by the trait fruit length to width ratio (107.14\%) and fruit yield per plant $(67.51 \%)$. The PCV and GCV 
were lowest for days to fifty percent flowering which was $8.55 \%$ and $7.91 \%$ respectively (Table 4).

Table 3b. Mean squares of analysis of variance among 56 accessions of eggplant.

\begin{tabular}{lllllll}
\hline SOV & df & PB & DF & DFF & NF & PH \\
\hline Replications (R) & 2 & $1.79^{* *}$ & $16.79 \mathrm{~ns}$ & $34.47^{* *}$ & $0.05 \mathrm{~ns}$ & $76.06^{*}$ \\
Accessions (A) & 55 & $4.95^{* *}$ & $144.91^{* *}$ & $127.60^{* *}$ & $253.63^{* *}$ & $615.71^{* *}$ \\
Countries (C) & $(2)$ & $7.23^{* *}$ & $13.66 \mathrm{~ns}$ & $123.93^{* *}$ & $1195.74^{* *}$ & $2027.92^{* *}$ \\
$\quad$ [A/C] & $(53)$ & $4.86^{* *}$ & $149.86^{* *}$ & $127.74^{* *}$ & $218.07 * *$ & $562.42^{* *}$ \\
Error & 110 & 0.16 & 6.15 & 6.74 & 0.9 & 16.7 \\
$\sigma^{2} \mathrm{a}$ & & 1.6 & 46.25 & 40.29 & 84.25 & 199.67 \\
$\sigma^{2} \mathrm{e}$ & & 0.16 & 6.15 & 6.75 & 0.89 & 16.7 \\
\hline
\end{tabular}

*Significant at $0.05, * *$ Highly significant at 0.01 and ns= non-significant, SOV: Sources of Variation, PB: number of Primary Branches Per Plant, DF: Days to first Flowering, DFF: Days to Fifty Percent of Flowering, NF: Number of fruits per plant, $\mathrm{PH}$ : Plant Height, $\mathrm{df}=$ degrees of freedom, $\sigma 2 \mathrm{a}=$ accession variance, $\sigma 2 \mathrm{e}=$ error variance, $[\mathrm{A} / \mathrm{C}]$ $=$ Accession within Countries.

Table 4. Estimated value of genetic parameters of different accessions of eggplant.

\begin{tabular}{lllllll}
\hline Traits & $\sigma^{2} \mathrm{~g}(\%)$ & $\sigma^{2} \mathrm{p}(\%)$ & $\mathrm{H}_{\mathrm{b}}{ }^{2}(\%)$ & $\mathrm{PCV}(\%)$ & $\mathrm{GCV}(\%)$ & GAM $(\%)$ \\
\hline FL & 23.32 & 24.24 & 96.20 & 37.88 & 37.14 & 75.05 \\
FD & 2.50 & 2.60 & 96.23 & 52.21 & 51.22 & 103.49 \\
FG & 25.69 & 26.81 & 95.84 & 52.24 & 51.15 & 103.15 \\
FW & 3896.07 & 3975.26 & 98.01 & 58.50 & 57.92 & 118.11 \\
FLWR & 44.41 & 50.26 & 88.37 & 113.98 & 107.14 & 207.48 \\
YPP & 137230.6 & 140013.7 & 98.03 & 68.19 & 67.51 & 137.71 \\
PB & 1.60 & 1.75 & 91.10 & 23.65 & 22.58 & 44.39 \\
DF & 46.25 & 52.40 & 88.27 & 9.68 & 9.09 & 17.59 \\
DFF & 40.22 & 47.12 & 85.66 & 8.55 & 7.91 & 15.08 \\
NF & 84.24 & 85.14 & 98.96 & 111.43 & 110.85 & 227.16 \\
PH & 199.70 & 216.41 & 92.28 & 19.60 & 18.83 & 37.26 \\
\hline
\end{tabular}

PCV: Phenotypic coefficient of Variation, GCV: Genotypic Coefficient of Variation, GAM: Genetic Advance of Mean, $\sigma 2 \mathrm{p}=$ Phenotypic Variance, $\sigma 2 \mathrm{~g}=$ Genotypic Variance, Hb2 $=$ Heritability, FL: Fruit Length, FD: Fruit Diameter, FG: Fruit Girth, FLWR: Fruit Length to Width Ratio, FW: Average Fruit Weight, YPP: Yield Per Plant, PB: number of Primary Branches per Plant, DF: Days to first Flowering, DFF: Days to Fifty Percent of Flowering, NF: Number of fruits per plant, PH: Plant Height.

\section{Heritability and genetic advance}

Estimation of heritability $\left(\mathrm{H}_{\mathrm{b}}^{2}\right)$ and genetic advance are presented in Table 4. Heritability and GAM values ranged between $85.66-98.96 \%$ and $15.08-227.16 \%$ respectively. Estimates of heritability were high (> 60.00\%) for all the traits. The estimates of GAM were also high for most of the traits except the traits days to first flowering and days to fifty percent flowering. These two traits showed moderate value of GAM. PCV and GCV are also important tools for the selection of 
Table 5. Mean performance of 56 eggplant accessions concerning quantitative characters.

\begin{tabular}{|c|c|c|c|c|c|c|c|c|c|c|c|}
\hline $\begin{array}{l}\text { Accession } \\
\text { name }\end{array}$ & $\begin{array}{l}\mathrm{FL} \\
(\mathrm{cm})\end{array}$ & $\begin{array}{l}\text { FD } \\
(\mathrm{cm})\end{array}$ & $\begin{array}{l}\text { FG } \\
(\mathrm{cm})\end{array}$ & $\begin{array}{l}\text { FW } \\
(\mathrm{g})\end{array}$ & $\begin{array}{l}\text { FLWR } \\
\text { (ratio) }\end{array}$ & $\begin{array}{l}\text { YPP } \\
(\mathrm{g})\end{array}$ & $\begin{array}{l}\text { PB } \\
\text { (no) }\end{array}$ & $\begin{array}{l}\text { DF } \\
\text { (days) }\end{array}$ & $\begin{array}{l}\text { DFF } \\
\text { (days) }\end{array}$ & $\begin{array}{l}\text { NF } \\
\text { (no) }\end{array}$ & $\begin{array}{l}\mathrm{PH} \\
(\mathrm{cm})\end{array}$ \\
\hline BB1 & 10.87 & 5.85 & 18.47 & 121.08 & 1.85 & 337.94 & 4.33 & 80.00 & 83.67 & 2.22 & 64.67 \\
\hline BB3 & 15.42 & 1.52 & 4.70 & 72.36 & 10.29 & 1395.10 & 6.89 & 69.00 & 78.00 & 20.33 & 86.22 \\
\hline BB4 & 12.63 & 3.32 & 10.84 & 130.72 & 3.80 & 343.12 & 6.11 & 81.00 & 84.33 & 1.67 & 76.44 \\
\hline BB5 & 14.18 & 6.28 & 19.96 & 224.27 & 2.26 & 859.75 & 6.89 & 74.33 & 77.33 & 4.45 & 87.00 \\
\hline BB6 & 12.17 & 3.60 & 11.65 & 154.21 & 3.40 & 1545.80 & 6.56 & 70.67 & 74.00 & 8.55 & 87.44 \\
\hline BB7 & 10.44 & 4.32 & 14.22 & 64.56 & 2.42 & 250.89 & 5.22 & 61.33 & 65.67 & 2.56 & 69.67 \\
\hline BB8 & 18.23 & 2.68 & 8.59 & 122.55 & 6.86 & 767.83 & 4.33 & 80.33 & 81.33 & 9.55 & 84.89 \\
\hline BB9 & 12.81 & 0.82 & 2.52 & 44.22 & 15.70 & 127.18 & 4.22 & 71.33 & 75.33 & 3.11 & 45.11 \\
\hline BB10 & 15.82 & 3.59 & 11.93 & 138.69 & 4.45 & 437.48 & 7.11 & 75.76 & 80.00 & 1.78 & 82.22 \\
\hline BB11 & 17.88 & 0.38 & 1.71 & 64.34 & 47.41 & 661.54 & 6.00 & 83.33 & 89.00 & 8.44 & 109.22 \\
\hline BB12 & 11.75 & 2.22 & 6.31 & 53.38 & 5.31 & 1418.30 & 7.67 & 63.33 & 74.00 & 27.67 & 86.56 \\
\hline BB13 & 14.30 & 1.78 & 5.74 & 79.83 & 8.07 & 918.81 & 6.56 & 68.67 & 75.67 & 12.00 & 68.28 \\
\hline BB14 & 8.82 & 3.50 & 11.15 & 54.22 & 2.54 & 166.58 & 5.22 & 59.33 & 64.00 & 2.33 & 77.89 \\
\hline BB15 & 11.93 & 6.51 & 20.50 & 261.20 & 1.84 & 1239.70 & 6.22 & 84.00 & 82.67 & 6.33 & 83.89 \\
\hline BB16 & 20.04 & 1.50 & 4.80 & 92.95 & 13.50 & 272.91 & 5.56 & 73.00 & 82.00 & 5.22 & 102.56 \\
\hline BB17 & 18.20 & 2.07 & 6.19 & 37.13 & 8.84 & 192.57 & 6.33 & 90.67 & 93.33 & 4.00 & 74.78 \\
\hline BB18 & 10.44 & 4.13 & 13.16 & 116.89 & 2.55 & 898.15 & 6.56 & 76.67 & 78.67 & 8.33 & 70.33 \\
\hline BB19 & 25.65 & 2.26 & 7.26 & 157.63 & 11.38 & 539.23 & 6.44 & 78.33 & 81.33 & 4.56 & 89.89 \\
\hline BB20 & 17.76 & 4.51 & 14.54 & 250.78 & 3.94 & 1240.30 & 6.56 & 71.67 & 78.00 & 13.11 & 85.22 \\
\hline BB21 & 10.45 & 2.53 & 7.98 & 82.11 & 4.17 & 244.70 & 4.44 & 65.33 & 71.67 & 3.11 & 46.72 \\
\hline BB22 & 17.58 & 4.96 & 16.23 & 234.32 & 3.54 & 1215.80 & 6.67 & 80.67 & 86.33 & 5.22 & 87.33 \\
\hline BB23 & 15.01 & 2.37 & 7.62 & 229.38 & 6.42 & 405.39 & 4.67 & 71.00 & 74.67 & 3.44 & 58.00 \\
\hline BB24 & 11.55 & 3.47 & 10.85 & 118.40 & 3.34 & 138.05 & 5.11 & 77.00 & 79.00 & 1.22 & 75.78 \\
\hline BB26 & 19.17 & 3.54 & 11.48 & 118.72 & 5.42 & 1043.20 & 6.56 & 67.33 & 72.67 & 10.00 & 91.11 \\
\hline BB27 & 14.03 & 5.05 & 16.48 & 140.28 & 2.77 & 172.50 & 4.22 & 87.00 & 90.00 & 1.33 & 65.00 \\
\hline BB28 & 14.17 & 3.62 & 11.52 & 158.24 & 3.94 & 267.44 & 6.56 & 77.67 & 81.67 & 1.22 & 77.94 \\
\hline BB30 & 10.04 & 3.81 & 12.43 & 89.89 & 2.64 & 744.29 & 3.89 & 79.67 & 86.33 & 7.11 & 57.83 \\
\hline BB31 & 10.87 & 5.59 & 17.81 & 149.29 & 1.98 & 455.13 & 5.22 & 67.00 & 74.33 & 2.67 & 75.22 \\
\hline BB32 & 10.80 & 5.75 & 18.79 & 129.35 & 1.88 & 168.73 & 3.89 & 73.33 & 78.33 & 0.89 & 66.44 \\
\hline BB33 & 14.36 & 0.76 & 2.26 & 64.15 & 20.04 & 295.12 & 5.11 & 77.00 & 80.00 & 3.55 & 99.89 \\
\hline BB34 & 15.72 & 2.03 & 6.54 & 105.10 & 7.80 & 223.14 & 5.22 & 71.33 & 74.00 & 3.55 & 73.94 \\
\hline BB35 & 9.93 & 1.81 & 5.81 & 58.76 & 5.51 & 184.49 & 3.22 & 78.33 & 84.33 & 4.78 & 71.55 \\
\hline BB36 & 13.34 & 4.41 & 13.87 & 168.89 & 3.04 & 799.23 & 5.78 & 79.00 & 83.67 & 5.89 & 81.17 \\
\hline BM3 & 13.78 & 1.69 & 5.81 & 97.19 & 8.25 & 558.68 & 4.45 & 75.67 & 80.67 & 9.89 & 76.66 \\
\hline BM4 & 13.86 & 3.86 & 12.22 & 175.93 & 3.63 & 759.79 & 5.11 & 62.00 & 71.67 & 6.33 & 85.67 \\
\hline BM5 & 17.67 & 2.38 & 7.45 & 139.75 & 7.49 & 1036.70 & 4.00 & 67.67 & 76.33 & 7.11 & 73.78 \\
\hline BM6 & 21.33 & 2.60 & 8.35 & 182.15 & 8.33 & 227.69 & 5.33 & 83.00 & 89.00 & 2.00 & 105.66 \\
\hline BM7 & 21.62 & 3.54 & 11.42 & 126.93 & 6.15 & 403.95 & 5.89 & 81.33 & 91.00 & 2.67 & 79.56 \\
\hline BM8 & 16.71 & 2.48 & 7.83 & 78.36 & 6.78 & 761.95 & 5.33 & 69.00 & 75.00 & 8.89 & 83.89 \\
\hline BM9 & 18.27 & 2.42 & 7.54 & 126.32 & 7.85 & 685.33 & 4.56 & 76.00 & 78.67 & 5.67 & 65.22 \\
\hline BM10 & 11.84 & 5.86 & 19.62 & 170.67 & 1.96 & 460.81 & 5.00 & 79.00 & 84.67 & 3.33 & 65.89 \\
\hline BT1 & 10.81 & 4.53 & 14.49 & 135.04 & 2.40 & 214.62 & 3.22 & 75.00 & 81.33 & 2.00 & 67.56 \\
\hline BT2 & 5.02 & 1.48 & 5.13 & 12.06 & 3.39 & 687.39 & 9.00 & 76.00 & 80.00 & 47.00 & 70.33 \\
\hline BT3 & 12.13 & 1.53 & 5.13 & 66.76 & 8.04 & 369.90 & 5.11 & 71.67 & 79.00 & 6.00 & 64.00 \\
\hline BT4 & 6.20 & 3.45 & 11.31 & 60.10 & 1.80 & 662.72 & 4.56 & 76.00 & 84.67 & 11.22 & 74.67 \\
\hline BT5 & 7.14 & 0.87 & 2.39 & 27.29 & 14.70 & 266.69 & 5.22 & 63.33 & 71.00 & 15.67 & 59.89 \\
\hline
\end{tabular}


Table 5 contd.

\begin{tabular}{llllllllllll}
\hline $\begin{array}{l}\text { Accession } \\
\text { name }\end{array}$ & $\begin{array}{l}\text { FL } \\
(\mathrm{cm})\end{array}$ & $\begin{array}{l}\text { FD } \\
(\mathrm{cm})\end{array}$ & $\begin{array}{l}\text { FG } \\
(\mathrm{cm})\end{array}$ & $\begin{array}{l}\text { FW } \\
(\mathrm{g})\end{array}$ & $\begin{array}{l}\text { FLWR } \\
(\text { ratio })\end{array}$ & $\begin{array}{l}\text { YPP } \\
(\mathrm{g})\end{array}$ & $\begin{array}{l}\text { PB } \\
(\mathrm{no})\end{array}$ & $\begin{array}{l}\text { DF } \\
(\text { days })\end{array}$ & $\begin{array}{l}\text { DFF } \\
(\text { days })\end{array}$ & $\begin{array}{l}\text { NF } \\
(\mathrm{no})\end{array}$ & $\begin{array}{l}\text { PH } \\
(\mathrm{cm})\end{array}$ \\
\hline BT6 & 5.19 & 1.88 & 5.78 & 7.52 & 2.76 & 188.15 & 8.89 & 82.33 & 96.00 & 15.44 & 60.22 \\
BT7 & 4.42 & 0.62 & 2.09 & 10.54 & 7.15 & 257.47 & 6.78 & 76.00 & 78.00 & 15.44 & 69.45 \\
BT8 & 17.82 & 2.90 & 9.44 & 104.04 & 6.15 & 452.27 & 7.22 & 78.33 & 82.00 & 4.56 & 83.55 \\
BT9 & 6.78 & 2.75 & 8.82 & 44.09 & 2.48 & 510.79 & 7.22 & 77.67 & 83.67 & 8.78 & 80.56 \\
BT10 & 17.90 & 2.76 & 8.58 & 124.16 & 6.49 & 246.24 & 4.89 & 80.33 & 86.33 & 3.22 & 87.22 \\
BT11 & 6.12 & 2.75 & 8.83 & 43.60 & 2.23 & 619.48 & 7.22 & 78.00 & 84.67 & 13.44 & 62.22 \\
BT13 & 13.60 & 1.76 & 6.38 & 36.18 & 7.73 & 432.05 & 6.33 & 69.33 & 75.67 & 33.00 & 44.89 \\
BT15 & 3.63 & 0.97 & 3.25 & 7.47 & 3.73 & 251.53 & 4.78 & 63.33 & 75.00 & 47.00 & 55.78 \\
BT16 & 9.53 & 5.16 & 16.06 & 96.29 & 1.85 & 362.28 & 4.11 & 88.00 & 93.67 & 3.22 & 78.22 \\
BT17 & 10.35 & 5.05 & 16.32 & 104.82 & 2.05 & 538.91 & 4.22 & 76.00 & 79.33 & 3.00 & 46.78 \\
Mean & 13.18 & 3.10 & 9.96 & 108.29 & 6.29 & 552.24 & 5.60 & 74.81 & 80.23 & 8.44 & 75.03 \\
LSD & 1.55 & 0.51 & 1.77 & 14.40 & 3.91 & 85.42 & 0.64 & 4.01 & 4.20 & 1.54 & 6.61 \\
\hline
\end{tabular}

Note: FL: Fruit Length, FD: Fruit Diameter, FG: Fruit Girth, FW: Average Fruit Weight, FLWR: Fruit Length to Width Ratio, YPP: Average Yield per Plant, PB: Number of Primary Branches per Plant, DF: Days to First Flowering, DFF: Days to Fifty percent of Flowering, NF: Number of Fruits per Plant, PH: Plant Height, LSD: Least Significant Difference

superior traits in breeding. All of the traits had high PCV and GCV except the traits days to first flowering and days to fifty percent of flowering. The highest GCV was recorded in the number of fruits per plant $(110.85 \%)$ and the highest PCV was recorded from the trait fruit length to width ratio (113.98\%). All traits assessed showed slightly higher PCV values compared to the corresponding GCV values. This means that there was little environmental influence on the expression of these traits.

\section{Correlation coefficient}

Simple correlation coefficients of phenotypic characters are shown in Table 6. Fruit yield per plant (YPP) is directly correlated with all the traits except days to the first flowering of the plant, days to fifty percent flowering of the plant and fruit length to width ratio. The correlation level of yield per plant with other traits ranged from $0.17-0.37$. The highest correlation value $(0.37)$ was observed from the correlation between average fruit weight and yield per plant. The second highest correlation (0.34) was between the numbers of primary branches per plant and yield per plant.

Table 6.Phenotypic correlation coefficient among different traits with yield per plant

\begin{tabular}{lc}
\hline Traits & rp with yield per plant (YPP) \\
\hline FL & $0.20^{* *}$ \\
FD & $0.18^{*}$ \\
FG & $0.17^{*}$ \\
FW & $0.37^{* *}$ \\
FLWR & $-0.04 \mathrm{~ns}$ \\
PB & $0.34^{* *}$ \\
DF & $-0.13 \mathrm{~ns}$ \\
DFF & $-0.13 \mathrm{~ns}$ \\
NF & $0.26^{* *}$ \\
PH & $0.33^{* *}$ \\
\hline
\end{tabular}

Note: *significant at 0.05 . ${ }^{* *}$ significant at 0.01 and ns= non-significant, FL: Fruit Length, FD: Fruit Diameter, FG: Fruit Girth, FW: Average Fruit Weight, FLWR: Fruit Length to Width Ratio, YPP: Average Yield per Plant, PB: Number of Primary Branches per Plant, DF: Days to First Flowering, DFF: Days to Fifty percent of Flowering, NF: Number of Fruits per Plant, PH: Plant Height, rp= Phenotypic correlation. 


\section{Cluster analysis}

The Euclidean distance was estimated by using standardized morphological data. An UPGMA (unweighted pair group method with arithmetic mean) dendrogram was constructed using the values of all morphological data for 56 eggplant genotypes. The genetic similarities varied from 0.92 to 7.97 . Seven main groups were determined among 56 genotypes at a value of 4.45 dissimilarity coefficient (Fig. 1) based on multivariate analysis. The value 4.45 was chosen for the convenience of explanation. The maximum number of genotypes (36) was recorded for group I which consisted of $64.28 \%$ of all genotypes in Table 7. Group II contained 5 genotypes (Table 7). Group III, IV, V, VI, and VII had 4, 4, 4, 2 and 1 accessions respectively (Table 7). The highest yield per plant (1350.6 g) was observed in cluster III (Table 8). The highest average fruit weight was observed in cluster IV (242.64 g), in combination with a moderate number of fruits per plant (7.28). Cluster VII was ranked third as it had moderate individual fruit weight $(64.34 \mathrm{~g})$ with a moderate number of fruits per plant (8.44). Cluster VI took place fourth position due to its highest number of fruits per plant (39.00) but the lowest number of average fruit weight $(24.12 \mathrm{~g})$. Cluster I and cluster II had the lowest yield per plant $459.12 \mathrm{~g}$ and $353.69 \mathrm{~g}$ respectively due to their low average fruit weight (Table 8). Group I had $459.12 \mathrm{~g}$ yield per plant due to its secondbest average fruit weight $(118.87 \mathrm{~g})$ with the lowest number of fruits per plant $(4.58)$. There was no obvious relation between the geographical area and grouping (Table 7). Genotypes from Bangladesh, Malaysia and Thailand clustered into the same group I due to their genetic reflection. The other accessions were also divided into groups based on their similarity in genetic variation mindless of their geographical area (Table 7).

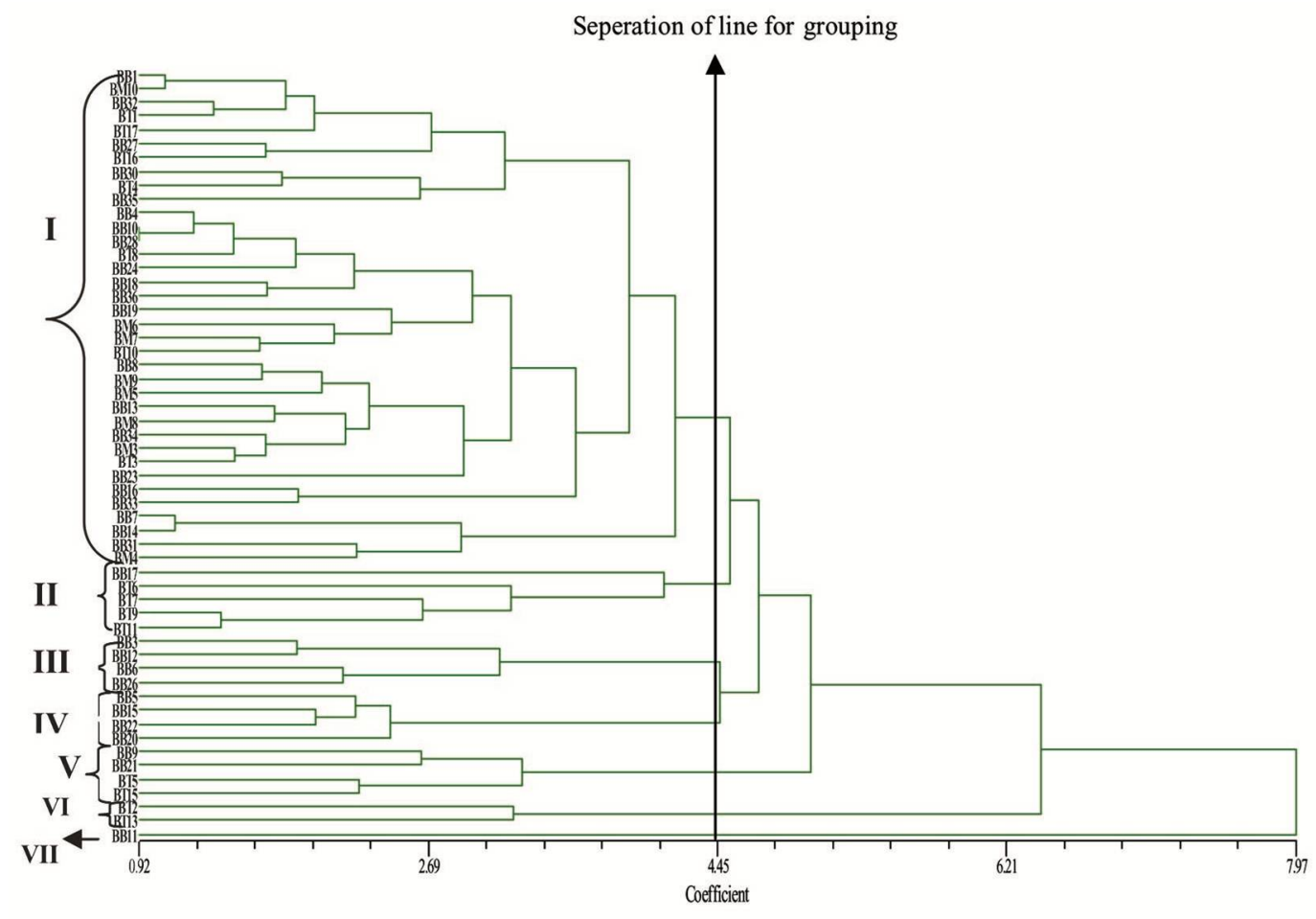

Fig 1. Cluster analysis of 56 eggplant genotypes based on quantitative traits. 
Table 7. Eggplant accessions clusters according to the group of origin.

\begin{tabular}{llll}
\hline Group & Bangladesh & Malaysia & Thailand \\
\hline I & BB1, BB32, BB27, BB30, BB35, BB4, & BM10, BM6, BM7, & BT1, BT17, BT16, \\
& BB10, BB28, BB24, BB18, BB36, & BM9, BM5, BM8, & BT4, BT8, BT10, BT3, \\
& BB19, BB8, BB13, BB34, BB23, BB16, & BM3, BM4 & \\
II & BB33, BB14, BB31, BB7 & & \\
III & BB17 & & BT6, BT7, BT9, BT11 \\
IV & BB5, BB15, BB22, BB20 & & \\
V & BB9, BB21 & & BT5, BT15 \\
VI & & & BT2, BT13 \\
VII & BB11 & \\
\hline
\end{tabular}

Note: BB: Brinjal Bangladesh, BM: Brinjal Malaysia, BT: Brinjal Thailand.

Table 8. Clustering and means of their quantitative traits.

\begin{tabular}{lccccccccccc}
\hline Cluster & FL & FD & FG & FW & FLWR & YPP & PB & DF & DFF & NF & PH \\
\hline I & 14.08 & 3.38 & 10.65 & 118.87 & 5.40 & 459.12 & 4.97 & 75.33 & 80.45 & 4.58 & 75.78 \\
II & 8.14 & 2.01 & 6.34 & 28.50 & 4.69 & 353.69 & 6.93 & 80.93 & 87.13 & 11.42 & 69.45 \\
III & 14.63 & 2.72 & 8.54 & 99.67 & 6.11 & 1350.60 & 6.25 & 67.58 & 74.67 & 16.64 & 87.83 \\
IV & 15.36 & 5.57 & 17.81 & 242.64 & 2.90 & 1138.92 & 6.42 & 77.67 & 81.08 & 7.28 & 85.86 \\
V & 8.51 & 1.30 & 4.03 & 40.27 & 9.57 & 222.52 & 4.58 & 65.83 & 73.25 & 17.22 & 51.88 \\
VI & 4.31 & 1.22 & 5.76 & 24.12 & 5.56 & 559.72 & 8.00 & 72.67 & 77.84 & 39.00 & 57.61 \\
VII & 17.88 & 0.38 & 1.71 & 64.34 & 47.41 & 661.54 & 6.00 & 83.33 & 89.00 & 8.44 & 109.22 \\
\hline
\end{tabular}

Note: FL: Fruit Length, FD: Fruit Diameter, FG: Fruit Girth, FW: Fruit Weight, FLWR: Fruit Length to Width Ratio, YPP: Average Yield per Plant, PB: Number of Primary Branches per Plant, DF: Days to First Flowering, DFF: Days to Fifty percent of Flowering, NF: Number of Fruits per Plant, PH: Plant Height.

\section{Principal component analysis (PCA)}

The Principal Component analysis (PCA) revealed that the first four components comprised $84.59 \%$ of total variation (Table 9). The PC1, PC2, PC3 and PC4 showed 31.21, 52.94, 70.15 and $84.59 \%$ of the cumulative variation respectively, which were explained in the Table 9 (eigenvector and eigenvalue analysis). In case of first principal component analysis, the most contributing traits were DF (0.227), FL (0.234), FD (0.471), FG (0.47) and FW (0.458). But for PC2, the most important traits were FLWR (0.477), PH (0.462), FL (0.433) DFF (0.32) and DF (0.314).

This research showed huge variation for the studied traits. Such considerable variation pointed out the scope for improving the characters concerning high yield. Similar results were recorded by Yadav et al. (2016) who reported significant variation in yield and yield-related traits of forty eggplant genotypes. Analysis of genetic variation for quantitative characters is a precondition in plant breeding programs. From this study, it was found that all the traits showed a higher PCV value than the corresponding GCV value. Slightly greater PCV from GCV was also obtained by Mili et al. (2014) and Rad et al. (2015). It indicates that the environmental influence on any trait is controlled by the enormity of the gap between the phenotypic and genotypic coefficient of variation; low difference indicates more prevalence of genetic influence. In contrast, large difference reveals a large environmental effect. From the study, all of the traits revealed little 
difference between them (PCV and GCV) indicated that the phenotypic expression of these traits had little environmental influence. It also indicates that the selection of these traits would hold effective for future hybridization. On the contrary, the high difference between PCV and GCV indicates the more environmental influence on the exposure of these traits. The high PCV and GCV was recorded for the traits FL, FD, FG, FW, FLWR, NF, YPP, and PB also recorded by the Pujer et al. (2017), Mili et al. (2014), and Rad et al. (2015). The lowest PCV and GCV were recorded for days to fifty percent flowering. This result is closely related with the findings of Vandana et al. (2014) and Mili et al. (2014).

Table 9. Eigenvectors and eigenvalues of the first four principal components of eleven traits.

\begin{tabular}{lcccc}
\hline Variable & PC1 & PC2 & PC3 & PC4 \\
\hline Eigen value & 3.43 & 2.39 & 1.89 & 1.59 \\
Variation (\%) & 31.21 & 21.72 & 17.21 & 14.43 \\
Cumulative (\%) & 31.21 & 52.94 & 70.15 & 84.59 \\
\hline FL & 0.234 & 0.433 & 0.156 & 0.288 \\
FD & 0.471 & -0.261 & 0.036 & 0.106 \\
FG & 0.47 & -0.262 & 0.033 & 0.106 \\
FW & 0.458 & 0.043 & 0.226 & -0.101 \\
FLWR & -0.187 & 0.477 & -0.016 & -0.247 \\
YPP & 0.105 & 0.064 & 0.586 & 0.204 \\
PB & -0.12 & 0.142 & 0.343 & 0.522 \\
DF & 0.227 & 0.314 & -0.396 & 0.389 \\
DFF & 0.163 & 0.32 & -0.402 & 0.438 \\
NF & -0.36 & -0.085 & 0.237 & 0.407 \\
PH & 0.153 & 0.462 & 0.294 & -0.028 \\
\hline
\end{tabular}

Note: FL: Fruit Length, FD: Fruit Diameter, FG: Fruit Girth, FW: Average Fruit Weight, FLWR: Fruit Length to Width Ratio, YPP: Average Yield per Plant, PB: Number of Primary Branches per Plant, DF: Days to First Flowering, DFF: Days to Fifty percent of Flowering, NF: Number of Fruits per Plant, PH: Plant Height, PC1: First Principal Component, PC2: Second Principal Component, PC3: Third Principal Component, PC4: Fourth Principal Component

All the variables have high heritability. Similar results reported by Jirankali et al. (2019) and Arunkumar et al. (2013). The GAM was also high for FL, FD, FG, FLWR, FW, NF, YPP, PH and PB that support to Jirankali et al. (2019) and Arunkumar et al. (2013). The moderate GAM was recorded for DF and DFF. Similar results found from the reporter Vandana et al. (2014) and Jirankali et al. (2019).

The selection for improvement of any character broad-sense heritability and GAM knowledge are important. The high heritability and high genetic advance percentage of the mean of the traits indicating, these characters mainly relied on genetic factors and can be acquired on the phenotypic perfection of these traits in crop improvement. So it is good for selection based on phenotypic traits to improve these specific characters. High heritability coupled with high GAM is also reported by Yadav et al. (2016), Mili et al. (2014) and Rad et al. (2015) in eggplant.

Correlation among different traits is very important for breeders because it helps to choose vital traits from the characters studied (Chattopadhyay et al., 2011). Most of the traits related to yield are controlled by genotype and environment interaction and hence it is easy to plant breeder to do selection based on correlation coefficient (Sohrabi et al., 2012). The traits days to the first 
flowering of plants and days to fifty percent flowering showed a negative correlation with total fruit yield per plant. From here, we concluded that delay in first flowering and fifty percent flowering improved fruit yield per plant. Fruit diameter and average fruit weight not only showed positively correlated with fruit yield per plant but also these traits are highly and positively significant with each other. Similar results were found by Rad et al. (2015). So selection based on any traits which are positively and significantly inter-related traits is good to get a desired interrelated response with other traits.

The 56 genotypes grouped into seven clusters based on the characters of cluster analysis at a distant coefficient of 4.45 indicate diversity level among the genotypes. Group VII, which has one genotype may have different genes as contrasted to others for regulating the characters. The diversity analysis of quantitative characters indicated the most similar accessions such as BB8 and BB4, BB10 and BB33 and BB15 and BB20 based on the distant coefficient, meaning that crossing among these accessions will not be useful. As these accessions have more or less same genetic makeup. However, cross between BB1× BT2, BT10 × BB11 and BB36 $\times$ BT6 will be useful, as these accessions were being most dispersive. Genetic diversity among 35 genotypes based on $\mathrm{D}^{2}$ statistics grouped into 10 clusters reported by Ravali et al. (2017). In this study, BB11 and BT2 for the individual group were distinguished from other accessions of other clusters that had a high genetic distance. Hybridization between the accessions of those clusters could be made following the findings of Tahir et al. (2013). The accessions of three different countries have the same genetic makeup and could be formed from the identical materials of breeding reported by Tahir et al. (2013). The accessions of the same group had genetic similarity and those were distributed randomly in several clusters had diverse though they had identical geographic regions reported by Balakrishna et al. (2017).

The PCA helps to explain how the similar genotypes group as compared to dissimilar genotypes. PCA can clarify the results of cluster analysis. The output of PCA supports the result of cluster analysis as for more precise and accurate data. Strong differences exist among the 56 genotypes in this research and these were also confirmed by PCA. Four principal components PC1 to PC-4 were extracted from the original data analysis having eigen values more than one reported by Kaiser (1960). The principal components of first four attributed to 85\% of the variation of whole variation which indicates that a strong correlation exists among all parameters studied. The value of first PC which subscribed $31.21 \%$ of the variation alone is most important. The trait fruit diameter (FD) contributed more to variation followed by fruit girth (FG), fruit weight (FW) and fruit length (FL) had the highest loading on PC1 which indicating significant importance of these components. Seventy entries of eggplant were studied by Sunseri et al. (2010) for determination of genetic diversity using PCA and denoted the first three components that attributed for $74 \%$ of the total variance which is more or less similar to these research findings $(70.15 \%)$.

\section{Conclusions}

This research exhibited the presence of genetic diversity among the 56 eggplant genotypes. This study also showed the significant economic traits which are important for the advancement of eggplant research. The aforementioned traits also showed a high genetic advance as a percentage of mean indicating all of these traits could be useful to select suitable accessions for a remarkable advancement in the breeding program. Based on yield performance, two groups, group III and group IV were indicated as proposed groups. Depending on the breeding objective, specific accessions would be identified from the core collection and would then be transplanted to the field, rather than maintaining the entire core collection in the field with the requirement to replant it every year. As a result, it will reduce maintenance costs in the field. 


\section{Acknowledgments}

The first author (DRD) would like to express her gratitude to the Bangabandhu Science and Technology Fellowship to select her as a fellow to continue a Ph.D. program at University Putra Malaysia (UPM). The author also would like to express her gratitude to the UPM specially Institute of Tropical Agriculture and Food Security (ITAFoS) for providing research facilities. She also thankful to the Bangladesh Agricultural Research Institute authority for approving deputation during her study period.

Conflicts of Interest: Authors have no conflict of interests regarding this publication.

\section{References}

Akhter, M.S., Ahamed, A. and Hossain, M.M., 2012. Agrobacteria mediated genetic transformation of eggplant (Solanum melongena L.). Inter. J. Pharm. Teaching \& Pract. 2: 275-280.

Arunkumar, B., Kumar, S.V. and Prakash, J.C., 2013. Genetic variability and divergence studies in brinjal (Solanum melongena L.). BIOINFOLET-A Quarterly Journal of Life Sci. 10(2b): 739-744.

Balakrishna, P., Pinnamaneni, R., Pavani, K.V. and Mathur, R.K. 2017.Genetic diversity in oil palm genotypes by multivariate analysis. Int. J. Curr. Microbiol. App. Sci. 6(8): 1180-1189.

Boyaci, H.F., Topcu, V., Akin, T.E.P.E., Yildirim, I.K., Mehmet, O.T.E.N. and Aktas, A., 2015. Morphological and molecular characterization and relationships of Turkish local eggplant heirlooms. Notulae Botanicae Horti Agrobotanici Cluj-Napoca, 43(1): 100-107.

Burton, G.W. and Devane, D.E., 1953. Estimating heritability in tall fescue (Festuca arundinacea) from replicated clonal material 1. Agronomy J. 45(10): 478-481.

Chattopadhyay, A., Dutta, S. and Hazra, P. 2011. Characterization of genetic resources and identification of selection indices of brinjal (Solanum melongena L.) grown in eastern India. Vegetable Crops Res. Bull. 74: 39-49.

Daunay, M.C., 2008. Eggplant. In: Vegetables II, Springer, New York, NY. pp. 163-220.

Dhaka, S.K., Kaushik, R.A., Jat, J. and Choudhary, R., 2017. Heterosis breeding in eggplant: A Review. J. Pharm. Phytochem. 6: 181-185.

Fraikue, F.B., 2018. Review of Historical, Health Benefts and Uses of Eggplants by Humankind. Asian J. Management, 9(1): 471-474.

Hurtado, M., Vilanova, S., Plazas, M., Gramazio, P., Fonseka, H.H., Fonseka, R.and Prohens, J., 2012. Diversity and relationships of eggplants from three geographically distant secondary centers of diversity. PLoS one, 7(7): e41748.

Jirankali, J. P., Reddy, N., Gangaprasad, S. and Manohara, S. N., 2019. Genetic variability for quantitative and qualitative characters in brinjal (Solanum melongena L.). Int. J. Curr. Microbiol. App. Sci. 8(3): 476-484.

Johnson, H.W., Robinson, H.F. and Comstock, R.E., 1955. Estimates of genetic and environmental variability in soybeans 1. Agronomy J. 47(7): 314-318.

Kaiser, H.F., 1960. The application of electronic computers to factor analysis. Educational and psychological measurement, 20(1): 141-151.

Khatun, M. T., Bari, M. A. A., Zaman, M. A., Begum, H. and Akter, S., 2010. Heterosis estimates in $F_{2}$ diallel population of spring wheat at two different cultural conditions. Bangladesh J. Agr. Res. 35(3): 413-422.

Lester, R.N. and Hasan, S.M.Z. 1991. Origin and domestication of the eggplant (Solanum melongena) from Solanum incanum in Africa and Asia. Solanaceae III: Taxonomy, Chemistry-Evolution. London: Royal Botanical Gardens Kew, pp. 369-387.

Mili, C., Bora, G.C., Das, B.J. and Paul, S.K. 2014.Studies on variability, heritability and genetic advance in Solanum melongena L. (Brinjal) genotypes. Direct Research Journal of Agricultural and Food Sci. 2: 192-194. 
Muñoz-Falcón, J.E., Prohens, J., Vilanova, S. and Nuez, F. 2009. Diversity in commercial varieties and landraces of black eggplants and implications for broadening the breeders' gene pool. Ann. Appl. Biol. 154(3): 453-465.

Myint, K.A., Amiruddin, M.D., Rafii, M.Y., AbdSamad, M.Y., Ramlee, S.I., Yaakub, Z. and Oladosu, Y. 2019. Genetic diversity and selection criteria of MPOB-Senegal oil palm (Elaeis guineensis Jacq.) germplasm by quantitative traits. Industrial Crops and Products, 139: 111558.

Pujer, P., Jagadeesha, R.C. and Cholin, S. 2017. Genetic variability, Heritability and Genetic Advance for Yield, Yield Related Components of Brinjal (Solanum melongena L.) Genotypes. Int. J. Pure Appl Biosci. 5(5): 872-878.

Rad, M. R. N., Poodineh, M., Ghalandarzehi, A. and Abkhoo, J. 2015.Variability, heritability and association analysis in eggplant (Solanum melongena L.). ARPN J. Agric. Biol. Sci.10(12): 464-468.

Ravali, B., Reddy, K.R., Saidaiah, P. and Shivraj, N. 2017.Genetic diversity in brinjal (Solanum melongena L.). Int. J. Curr. Microbiol. App. Sci. 6(6): 48-54.

Rodríguez-Burruezo, A., Prohens, J. and Nuez, F. 2008.Performance of hybrids between local varieties of eggplant (Solanum melongena) and its relation to the mean of parents and to morphological and genetic distances among parents. European Journal of Horticultural Science, 73(2): 76.

Sarif, H.M., Rafii, M.Y., Ramli, A., Oladosu, Y., Musa, H.M., Rahim, H.A., Zuki, Z.M. and Chukwu, S.C. 2020. Genetic diversity and variability among pigmented rice germplasm using molecular marker and morphological traits. Biotechnology \& Biotechnological Equipment, 34(1): 747-762.

Shrestha, J. 2013. Agro-morphological characterization of maize inbred lines. Wudpecker Journal of Agricultural Research, 2(7): 209-211.

Sivasubramanian, S. and Menon, M. 1973.Heterosis and inbreeding depression in rice. Madras Agric. J. 60(7): 1139-1140.

Smith, J.C. and Smith, O.S. 1989. The description and assessment of distances between inbred lines of maize II: The utility of morphological biochemical, and genetic descriptors and a scheme for the testing of distinctiveness between inbred lines. Maydica, 34(2): 151-161.

Sohrabi, M., Rafii, M.Y., Hanafi, M.M., Siti, A. and Latif, M.A. 2012. Genetic diversity of upland rice germplasm in Malaysia based on quantitative traits. The Scientific World Journal, 2012: 1-9.

Strelchenko, P., Okuizumi, H., Shehzad, T., Malinovskaya, E., Kawase, M., Fukuoka, S. and Okuno, K. 2010. Genetic relationships of sorghum germplasm in Asia and Africa revealed by rice cDNA-STS and indel markers. Japan Agricultural Research Quarterly: JARQ, 44(3): 259-268.

Sulaiman, N.N.M., Rafii, M.Y., Duangjit, J., Ramlee, S.I., Phumichai, C., Oladosu, Y., Datta, D.R. and Musa, I. 2020. Genetic Variability of Eggplant Germplasm Evaluated under Open Field and Glasshouse Cropping Conditions. Agronomy, 10(3): 436.

Sunseri, F., Polignano, G.B., Alba, V., Lotti, C.O.N.C.E.T.T.A., Bisignano, V., Mennella, G., Drsquo, A., Bacchi, M., Riccardi, P., Fiore, M.C. and Ricciardi, L. 2010.Genetic diversity and characterization of African eggplant germplasm collection. African J. Plant Science, 4(7): 231-241.

Tahir, M., Rahman, H., Gul, R., Ali, A. and Khalid, M. 2012. Genetic Divergence in Sugarcane Genotypes. Journal of Experimental Agriculture International, 3(1): 102-109.

Van der Weerden, G.M. and Barendse, G.W. 2006. A web-based searchable database developed for the EGGNET project and applied to the Radboud University Solanaceae database. In: VI International Solanaceae Conference: Genomics Meets Biodiversity, 745: 503-506.

Vandana, Y., Nandan, M., Rangare, S.B. and Eshu, S. 2014. Variability and heritability estimates in the germplasm collection of egg plant (Solanum melongena L.). Trends in Biosciences, 7(21): 3482-3484.

Yadav, N., Dhankar, K.S., Chandanshive, A.V. and Kuma, V., 2016.Studies on variability, Heritability and Genetic Advance in brinjal (Solanum melongena). The Bioscan, 11(4): 3001-3005. 